\title{
Imagem e fenomenologias da autoctise histórica: a relevância da análise onírica na psicoterapia ontopsicológica
}

\author{
Fernanda Goulart Martins ${ }^{1}$
}

\section{INTRODUÇÃO}

A importância do estudo das imagens e dos sonhos é reconhecida há milhares de anos. "Em todas as épocas históricas, o sonho inspirou a especulação filosófica e causou fascínio à imaginação humana" (GUTHEIL, 1951, p. 6). De fato, "o sonho é uma verdade objetiva do sujeito" (MENEGHETTI, 2012a, p. 252), e pode ser definido como "feixe de projeções imaginativas que identificam o estado real do sujeito no plano biológico, psicológico e ôntico" (p. 250). A partir desse entendimento, a análise onírica, segundo a metodologia ontopsicológica, consente examinar o interior de uma ação e permite chegar à formalização da intuição que cada sujeito pode colher, como previsto por natureza.

O sonho, então, revela-se um importante instrumento em psicoterapia. Entretanto, o estudo de diferentes linhas teóricas e metodológicas leva ao reconhecimento de que diversas abordagens da clínica psicoterapêutica conduzem modos distintos de analisar os sonhos:

\begin{abstract}
Em relação à função do sonho como instrumento psicoterapêutico, cada uma das abordagens tem sua concepção, sendo que na abordagem psicanalítica é utilizado como realização de desejo, já na abordagem junguiana, o uso do sonho tem função de auxiliar no processo de individuação, por fim a abordagem cognitivo comportamental, que utiliza o sonho para atingir a autocompreensão do cliente (MACHADO e ALVES, 2009, p. 416).
\end{abstract}

Segundo a metodologia ontopsicológica, independentemente das convicções conscientes que alguém possa ter, a gráfica onírica assinala o erro e o sucesso segundo uma hierarquia e, assim, mostra a diretividade que, se analisada corretamente e seguida, aponta a escolha otimal em qualquer tomada de decisão:

Para saber qual é a escolha justa a fazer, é preciso saber ler os sonhos: a Ontopsicologia descobriu como decodificar os símbolos oníricos, tomando o sentido de exatidão da idêntica lógica que a natureza usa no interior do próprio sistema subatômico celular (MENEGHETTI, 2012b, p. 251).

\footnotetext{
${ }^{1}$ Professora na Faculdade Antonio Meneghetti e Doutoranda em Psicologia Social e Institucional na UFRGS.
} 
O avanço tecnológico e a produção científica em intensificação nos nossos tempos vêm produzindo ferramentas, métodos e publicação de informações que auxiliam no gerenciamento do tempo, das tarefas e também das escolhas no dia-a-dia. Entretanto, a necessidade da obtenção de um critério parece ser ainda mais importante. Através dos meios de comunicação, o acesso é livre a opiniões e constatações, publicadas em artigos (científicos ou não), mas a carência de parâmetros dificulta a escolha da informação útil para a situação que se busca resolver.

Cada momento de tomada de decisão é uma oportunidade para fazer aquela escolha que proporciona crescimento, aprendizagem e reforça a identidade. Em prática clínica da psicoterapia, tem-se a evidência diariamente de que, sem um critério, o processo psicoterápico pode facilmente tornar-se uma prática feita às cegas, um percurso dirigido inconscientemente pelas projeções e convicções do terapeuta ou por armadilhas das transferências. Percebe-se a necessidade latente de problematizar como e por que determinadas direções são dadas em psicoterapia: "Descrever precisamente o que os terapeutas fazem em sessão, e como o fazem, é um desafio para os estudos em psicoterapia. Pouco se conhece sobre as variáveis importantes que direcionam as decisões terapêuticas" (MOURA et al., 2009, p. 174). As variáveis relevantes que levam um terapeuta a decidir por tomar uma direção ou outra dentro da condução de um tratamento ainda é tópico de estudo e discussão (HAGOPIAN et al., 1997).

Se o sonho formaliza-se sempre a partir das exigências vitais do indivíduo (MENEGHETTI, 2012a), ele pode dar o critério no processo de escolha, em qualquer campo de investimento: em aspectos da situação orgânica do sujeito, das referências afetivas e/ou dos âmbitos profissional, empresarial e social. Em psicoterapia ontopsicológica, para além das opiniões e convicções de cada pessoa, individua-se a intencionalidade de natureza, considerando-se possível colhe-la no sonho, e então decidir por atuar a escolha otimal; aquela que faz funcionalidade, incremento, saúde, globalidade, integralidade à identidade.

Este trabalho se desenvolve com o objetivo primário de verificar resultados de tomadas de decisão baseadas na análise onírica, segundo o método ontopsicológico e operada em setting terapêutico. Como objetivo secundário, intenciona-se (a) Conhecer os resultados obtidos no percurso existencial de sujeitos que seguiram a diretividade apontada pela análise onírica, e coloca-los em comparação com os efeitos colhidos pelos sujeitos que não decidiram agir de acordo com a solução apontada pela análise do sonho. Busca-se, assim, compreender se há diferenças significativas em relação à manifestação do estado de saúde física, e à 
manifestação de medo e angústia nos processos decisórios de quem se interessa e quem não se interessa por dar existência histórica à intuição projetada na imagem onírica. Também cabe como objetivo secundário (b) colher, através dos desenhos do teste projetivo (T6D), intenções inconscientes ou conscientes a respeito da personalidade dos participantes e da disponibilidade para o crescimento próprio.

A imagem contém a ação e age produzindo, inevitavelmente, efeitos concretos. Para considerar o sonho um critério, tem-se como base o estudo da reversibilidade entre imagem e ação. Por meio da leitura da forma, pode-se conhecer e decidir por atuar historicamente escolhas que levam à saúde, à funcionalidade e à integralidade da própria identidade.

\section{Fundamentação Teórica}

\subsection{Falta de parâmetros: obstáculos do processo de decisão}

Momento a momento, o ser humano faz decisões: onde trabalha, com quem conversa, quando deve se expor, quanto deve investir em um novo projeto, em qual momento deve deixar de agir de determinado modo e tantas outras questões se colocam diariamente. Faz-se necessário algum parâmetro na gestão da própria construção histórico existencial. Mas que tipo de realização se procura? É possível medi-la? Quem busca, por exemplo, consultoria para resolver qualquer tipo de problema individual, sabe dizer onde quer chegar? Compreende a singularidade da sua intenção? Todos os seres humanos se realizam do mesmo modo? $\mathrm{O}$ sucesso para cada um tem o mesmo significado? Os parâmetros para a ambição de cada ser humano são iguais? Com que critério age um operador de mudança da sociedade?

Meneghetti (2002, p. 15) explica que, atualmente, falta "um vetor unitário à globalização em ato, um critério genérico de referência ao mover-se desta humanidade" e, com isso, coloca-se tudo em crise. Ele assinala três fatores relacionados a esse fato: $a$ globalização em ato, a preocupação presente em todos os chefes políticos e religiosos do mundo, e os jovens.

A globalização em ato é um dos fatores porque leva para cada casa desse planeta uma cultura futurística que é difundida pela televisão, pelos satélites, pelo mercado dos melhores e mais avançados. "Não é o mercado popular a caminhar em todo o mundo, mas o mercado mais sofisticado. Tudo que existe de mais qualificado, hoje, está ao alcance de todos e [...] todos querem o objeto mais sofisticado. Isso significa automaticamente a subversão e a perda de qualquer passado" (MENEGHETTI, 2002, p. 15). Essa situação tende a uma desigualdade mais forte, e a uma desproporção entre nações e pessoas, uma vez que 
algumas nações tornar-se-ão sempre mais potentes, enquanto a maioria das pessoas terá a normal pobreza e estabilização das exigências biológicas. [...] Os povos pobres poderão ter somente mercado e, se não estudarem e se desenvolverem, é inevitável sua regressão sócio-política e psicológica (pp. 15-16).

A preocupação presente em todos os chefes políticos e religiosos é um fator que diz respeito à necessidade sentida pelos chefes de movimentos intelectuais ou filosóficos de se unirem para sobreviver. "Estamos no mais aberto pluralismo relativístico" (p. 17).

Por último, os jovens constituem um dos fatores relacionados à falta de parâmetros. Por jovens, aqui, entende-se aqueles na faixa etária dos quatorze aos trinta anos, aproximadamente. Entende-se que em todo o planeta têm nascido inteligências particulares, indivíduos que parecem ter uma cultura e um conhecimento muito superiores à idade que têm. No plano prático-consciente, estão à espera de assumir o poder social. Jovens que estão em uma dimensão própria:

\footnotetext{
fingem escutar os professores, os pais, os sacerdotes, apenas para aprender como raciocina o mais velho, mas o aprendem já adultos por uma outra dimensão que estes sentem superior em si mesmos. [...] Escutam somente para se informar de como pensa "alguém do passado". No plano prático-consciente, estão à espera de assumir o poder social (pp. 17-18).
}

Trata-se de uma carência de princípios para formalizar um futuro geral, principalmente se tiver a ambição de um protagonismo na existência. Meneghetti (2002) finaliza a descrição dos três fatores, acima citados, afirmando, frente a uma análise dos fatos, que se pode facilmente chegar à conclusão de que quase todos são um pouco doentes e é difícil encontrar um ser humano sadio. O problema fundamental, esclarece o autor, é exatamente o de refundar um critério ético dentro do humanismo. A Ontopsicologia traz conhecimento e método que permitem afrontar esse problema.

É preciso, primeiro, levar em conta os obstáculos encontrados pelo ser humano no conhecimento de si mesmo e na construção existencial em devir. Um deles é a do inconsciente em operação: "O inconsciente é o quântico de vida psíquico e somático que o indivíduo é, mas do qual não é consciente e que, contudo, age para além da lógica da consciência” (MENEGHETTI, 2010, p. 210). Esse quântico existencial é ativo e não verificável pelo conhecimento responsável ou voluntário. Não foi determinado pela natureza do ser humano e resulta na realidade de ignorância do homem acerca de si mesmo. 
Com os estudos de Freud, nos séculos XIX e XX, o inconsciente recebeu esse nome e foi pesquisado, mas é uma realidade que já existia e que indica o caminho de onde se parte para responder as questões colocadas pelo (e ao) ser humano. "Para Freud, entretanto, faltou o acesso à natureza real do homem: ele não viu o aspecto positivo da natureza e nem a exatidão da inteligência desta mesma natureza" (VIDOR, 1996, p. 53). Evidencia-se um outro mundo no ser humano, que antecipa aquele consciente e racional, condicionando e alterando o seu comportamento. "Todos os homens são direcionados por esse mundo oculto, negro, que permanece fechado a qualquer possibilidade de indagação consciente e racional" (MENEGHETTI, 2010, p. 119). Pode-se concluir, que, se é reconhecida a importância de conhecer a realidade e indagar sobre ela, deve-se recuperar a consciência de si, antes de operar sua profissão. "É nas camadas da subjetividade que habita o maior potencial de inteligência do homem que, enquanto não for recuperado, produzirá ações incompreendidas e inexplicáveis" (VIDOR, 1997, p. 13).

\section{a. A convenção e a natureza}

Os critérios, para produzir ciência e gerir a própria história existencial, podem ser de dois gêneros: o critério convencional (a opinião) e o critério de natureza. O critério convencional é aquele estabelecido e definido para que se possa proceder sempre com base na mesma medida preestabelecida. É como a definição do metro, que, depois de feita, é seguida por todos da mesma forma para o trabalho com medidas espaciais. "Nas ciências oficiais, baseadas no critério convencional, quando o critério não é adaptável à ideologia, o discurso não é considerado válido. Isso significa que não se busca o que é real, mas sim o que é conforme" (MENEGHETTI, 2010, p. 147). O critério convencional responde sempre à intencionalidade de um grupo, que pode ser social, filosófico, teológico ou pragmático.

O critério de natureza "é uma medida que procede por evidência [...] e concretiza o objeto ou o campo pré-escolhido" (p. 147). É o único capaz de oferecer o critério de exatidão para julgar qualquer acontecimento, a medida que a natureza já tem na sua base uma lei fundamental, à qual o homem não pode se subtrair, porque existe. O critério de natureza não é subjetivo, é anterior à subjetividade histórica.

Para exemplificar o que significa um critério anterior à subjetividade histórica, poderse-ia ousar a seguinte explicação: um conjunto de pessoas define que determinada distância será identificada como metro para medir qualquer espaço (critério convencional) e, com isso, cria-se a convenção de que todas as medições deverão seguir aquele critério, o metro. Mas, se 
um conjunto de seres humanos quiser definir que um ser humano tem valor pelo quanto de pedras conseguir comer e digerir, o resultado trará sérios problemas. Não se pode escolher para si mesmo algo que diverge da própria natureza. A incapacidade que um ser humano tem de comer e digerir pedras é anterior à cultura, às convicções e à subjetividade histórica. Cada pessoa é um projeto objetivo, que se especifica conforme faz-se na história. Contradizê-lo em nome das convicções ou convenções gera sempre frustração: espera-se um resultado e não se obtém retorno.

O critério fundamental da natureza é o que se define por Em Si do homem: "a ordem apriórica e categórica de qualquer ser humano" (MENEGHETTI, 2010, p. 148). Segui-lo como critério significa que partimos de onde somos reais, de onde existimos.

A verificação do critério faz-se nos fatos, porque "o critério da vida carrega consigo os fatos da vida" (MENEGHETTI, 2010, p. 150).

\footnotetext{
O que é conforme ou coincidente ao Em Si ôntico é sanidade e criatividade para o homem, no plano biológico (=plano total de saúde em sentido médico), psicológico (personalidade funcional; entre as funções da personalidade está também a inteligência, a lógica, o pensamento, a reflexão a exigência de verdade) e social (=funcionalidade em todos os setores da sociedade, como, por exemplo, economia, política, efetividade, pesquisa etc.) (MENEGHETTI, 2010, p. 166).
}

Assim, pelo critério de natureza, é possível saber qual é a melhor escolha a ser feita (não por cálculo de riscos, mas a melhor na qualidade de única escolha otimal), momento a momento, no aqui agora existencial.

\section{b. Ferramentas teóricas e conceituais para a identificação da escolha otimal na fenomenologia da imagem onírica}

Uma vez que a Ontopsicologia permite a entrada no primeiro interior das causas dos processos psíquicos, ela possibilita colher a imagem que "exprime a vetorialidade otimal da situação entre Eu e mundo, em vantagem do Eu integral ou Em Si organísmico”. Ela "constitui aquele possível otimal a ser concretizado por sucessiva tomada de consciência e de vontade, para o nascimento constante do Eu histórico em processo intrínseco" (MENEGHETTI, 2012a, p. 105). A identificação da virtualidade da informação ôntica, constitui-se, então, um critério, que faz reversibilidade com o real, ou seja, a tomada de decisão leva ao crescimento e à realização.

O devir existencial implica passagens psicológicas, módulos comportamentais relativos à economia, ao sexo, à mentalidade, ao business, à evolução. Por natureza, é previsto 
que o ser humano se desenvolva segundo fases progressivas da autóctise histórica, que significa a "autoprodução de si mesmo em conformidade ao próprio Em Si ôntico" (MENEGHETTI, 2013, p. 30). Para além de descrever essas fases teoricamente, a Ontopsicologia apresenta ferramentas conceituais, de diagnose e de intervenção para possibilitar a compreensão de fenômenos humanos e da possibilidade da autoprodução de si em coerência com o projeto de natureza.

A compreensão acerca da imagem como alfabeto da energia é descrita por Meneghetti (2005), que afirma-a como uma técnica científica que se coloca alguns fins, e individuou os modos e os meios para realizar estes fins. Para isso, primeiro há uma técnica, uma passagem: fazer bem as pequenas coisas de todo dia.

Temos um juiz da nossa administração quotidiana: o sonho. Em diferentes momentos históricos da humanidade, os sonhos parecem despertar curiosidade, seja por seu caráter premonitório, seja por parecerem-se com uma espécie de fenda que permite colher alguma informação advinda do inconsciente. Tal curiosidade não se daria por acaso: o sonho revela o máximo de realidade que um ser humano vive em um determinado momento. É “o espelho holístico da atividade orgânica e funcional do nosso existir” (MENEGHETTI, 2012a, p. 250).

A análise onírica é um instrumento de critério diagnóstico, tendo como fím a autenticação do ser humano e a abertura à atuação da criatividade. Porém, "para ser admitido no interior desse arquivo de atividade lógica, devemos possuir a introdução linguística. Exatamente como não podemos saber o que um indivíduo diz, se não possuímos o código da língua que ele usa para se exprimir” (MENEGHETTI, 2010, pp. 296-297).

O sonho completo sempre expõe a situação atual, a causa e a solução. As instâncias que contribuem para a formação do sonho são a memória, o Eu ideal, o organismo, o monitor de deflexão e o Em Si. A memória, porque a consciência pode recordar apenas o que já fora fixado. O Eu ideal representa as aspirações e referências ideais do sujeito. O organismo, no que consente a necessidade de satisfação das exigências orgânicas. $\mathrm{O}$ monitor de deflexão se constitui uma das instâncias na medida em que pode induzir um sonho e, nesse caso, pode-se identifica-lo na presença de imagens precisas e categóricas. Já o Em Si fornece a ótica total da vida em relação ao quadro geral do indivíduo. A referência de todas essas instâncias é o Eu psicológico.

A leitura do sonho deve ser feita exclusivamente na lógica funcional do sonhador e o critério universal para ler o símbolo no sonho é o biológico. 
O método para ler o sonho, segundo a ciência ontopsicológica, baseia-se em três princípios universais de análise do símbolo, quatro fontes das quais derivam os símbolos e quatro aspectos para serem lidos na cena onírica. A eles é acrescido ainda a imissão informática ou interferência programática do monitor de deflexão, que no interior dos sonhos sempre faz sua marca.

Depois, os critérios de verificação sobre um signo são três: (1) natureza causal, que significa verificar o valor do símbolo com base na utilidade real conhecida pelo ser humano neste planeta, (2) Efetualidade funcional do símbolo para o sujeito, isto é, o que o símbolo produz para o sujeito aqui e agora, (3) e o critério semântico, através do qual o técnico pode distinguir o sonho verdadeiro do sonho falso, e colher a diretividade ôntica, que "é a volição contínua à autorrealização do sujeito" (MENEGHETTI, 2010, p. 301).

As fontes da psicogênese do símbolo são: a realidade social, a visualização dos nossos instintos, as formalizações semânticas derivadas do externo e as pulsões meta-históricas da humanidade. Já o aparato cênico narrativo da direção onírica são ação em mutação, ambiente, pessoas ou indivíduos, e os sentimentos. "Quando o sonho dá imagens, não são símbolos, mas deslocamentos de realidade" (MENEGHETTI, 2010, p. 54). Os signos apresentados no sonho são formas que carregam energia psíquica e dão a ela um escopo, um vetor, uma direção.

\section{c. Imagem como critério na prática psicoterápica: diretividade para a autenticação e autonomia do cliente no processo de tomada de decisão}

Os instrumentos metodológicos que permitem identificar a escolha otimal que se apresenta momento a momento têm por objetivo consentir a autenticação do homem. Consultorias individuais e a psicoterapia constituem-se, entre outros, instrumentos de intervenção propostos pela Ontopsicologia. Psicoterapia significa a "análise dos processos psíquicos para individuar o ótimo de comportamento global do sujeito" (MENEGHETTI 2012a, p. 227). Sendo assim, pode-se compreendê-la como uma ferramenta que permite ao cliente o direcionamento da própria existência segundo o critério de natureza e isso se refere à possibilidade de "ver aonde a ação psíquica vai, onde é impedida e como ajudar a pulsão constante variando os comportamentos do Eu consciente sem jamais the inserir nada alheio" (p. 228).

O fim primário e único da psicoterapia é a autenticação do humano, enquanto o fim secundário é o desaparecimento do sintoma. Para tais fins, o percurso psicoterapêutico possibilita 1) a identificação do Em Si; 2) a autenticação; e 3) a evolução. A identificação do Em Si 
é já um grande empenho, porque se deve passar através de tantos véus constituídos pelos estereótipos, pelos complexos e pelas ideologias sobre a verdade: estereótipos são os modos de conduta de um sistema; complexos são as deformações estruturais que, do núcleo familiar, inseriram-se no amadurecimento existencial do sujeito; ideologias são tudo aquilo que é considerado absoluto. Esses três fatores agem de modo sinérgico estão em interação contínua e um se esconde no outro (MENEGHETTI, 2010, p. 311).

O processo de autenticação se dá na medida em que o Eu lógico-histórico é correspondente ao previsto pelo desenho operativo da natureza do sujeito. A autenticidade é "um pôr-se histórico conforme a própria origem metafísica por meio do real mais aderente. A realidade, de qualquer experiência que seja, diz-se mais aderente somente quando o impacto com ela consente, no indivíduo homem, a melhor gestalt do originário metafísico no contexto histórico do indivíduo" (MENEGHETTI, 2003, p. 47). A evolução é compreendida no percurso ontoterapêutico como "ação à própria ulterior virtualidade (sendo o homem um projeto virtual aberto)" (MENEGHETTI, 2010, p. 311), e ocorre depois de feita a identificação, e de reativada a autenticidade.

A psicoterapia, em seu caráter diretivo, propõe que o terapeuta comece a impulsionar na direção já assinalada pela espontaneidade do inconsciente do cliente. "Entre as características que qualificam e distinguem a nossa escola existe a diretividade ôntica”, isto é, "verbalizar o formal intencionado pelo Em Si inconsciente do sujeito" (MENEGHETTI, 2004a, p. 218). “O esquema-base do processo ontoterapêutico é: individuar a pulsão ou intencionalidade do Em Si ôntico no aporético contexto psicológico do indivíduo (tecido anamnéstico), evidenciar a sua exigência autêntica em ação situada e provocar sua atuação possível” (MENEGHETTI, 2010, p. 310). Assim, o "objeto específico da psicoterapia em sentido ontopsicológico é verificar, identificar, recuperar a intencionalidade da ecceidade do Em Si, porque onde se intenciona o Em Si, lá e assim eu sou, lá e assim eu devenho e sou existência" (MENEGHETTI, 2004a, p. 156).

Com base em um critério, pode-se fazer realidade, autoridade, certeza, dialética, verdade, funcionalidade. Não pode existir contradição entre o critério de natureza (Em Si ôntico) e os fatos, "porque critério da vida carrega consigo os fatos da vida. A solução para sair de qualquer problema está em seguir os elementos que o iso identifica como próprios da ótica ecceica do indivíduo" (MENEGHETTI, 2010, p. 150). Iso é conceituado como "uma forma lógica que preside qualquer estruturação do nosso organismo"; "o critério-base da sanidade da vida, igual, seja para a célula, seja para a estrutura orgânica, para o organísmico, para os comportamentos cerebrais, para a fantasia etc" (MENEGHETTI, 2012a, p. 146). 
O processo diagnóstico para a condução de qualquer processo de intervenção implica verificar se uma escolha, uma tomada de decisão, um direcionamento, é feita em congruência com a diretividade ôntica. A escola ontopsicológica propõe percursos fenomênicos para identificar e aplicar o iso ao holístico-dinâmico da pessoa: (1) a anamnese linguística e biografia histórica, (2) a análise do sintoma ou problema, (3) a análise fisionômico-cinésicoproxêmica, (4) a análise onírica, (5) a análise semântica e (6) o resultado. "O uso sincrético e contemporâneo de tais linguagens consente as interceptações do Em Si ôntico" (MENEGHETTI, 2010, p. 167). Esses percursos fenomênicos são aplicados no processo diagnóstico, proporcionando a profissionais de diferentes áreas do conhecimento a total compreensão da situação, o problema, sua causa e a solução.

Para além da diagnose, que é realizada novamente a cada sessão, o processo ontoterapêutico possui um esquema lógico, que é articulado em cinco tempos: (1) situação de impacto, (2) anamnese retroativa, (3) diagnose fideística, (4) individuação do Em Si ôntico e (5) verbalização raciocinada e repetida do Em Si ôntico (psicoterapia centrada sobre a pulsão) (MENEGHETTI, 2010). O primeiro tempo define que o psicoterapeuta impacta o cliente em disponibilidade à sua novidade, ausculta e interpreta sobretudo as mensagens inconscientes, e percebe a discordância entre expressão lógico-verbal e a cinessomática. O segundo tempo se trata do momento de habituar o cliente à introspecção, de conhecer o panorama do ambiente familiar, de trabalho, dos interesses pessoais, sociais, afetivos. Aqui, ocorre a indicação precisa do problema, e o cliente deve reencontrar todas as negações ou deformações, que impôs a determinadas experiências, a partir das quais o crescimento pessoal se bloqueou. No terceiro tempo, compreende-se o esquema de referência interna ideal e emotiva do cliente. No quarto tempo, o cliente deve colher a unidade do próprio dever ser, e na quinta fase, o ontoterapeuta chama constantemente o cliente à atenção de si. A diretividade empática do terapeuta deve centrar o cliente, "para que seja capaz de auscultar-se onticamente e individuar-se originalmente. A diretividade não é imposição externa, mas ausculta no mais íntimo como determinante último" (p. 320).

Uma vez que o critério de natureza é distribuído no campo existencial do sujeito, constituindo-se "aquele valor-base presente em todos os aspectos da personalidade" (MENEGHETTI, 2004a, p. 266), é possível então estudar os resultados, os efeitos de escolhas feitas em acordo ou desacordo da diretividade ôntica. "O iso é determinado pela constante presença em todas as análises: fenomenicamente exprime-se, evidencia-se em uma constante". Com "fenomenicamente" entende-se "qualquer coisa real: a pele, os cabelos, 
aquilo que como, o tumor, a morte, o nascimento. É fenomênico qualquer coisa ou aspecto que é objeto da percepção dos sentidos” (MENEGHETTI, 2004a, p. 267).

Para analisar a tomada de decisão no processo psicoterapêutico considera-se que seus efeitos são colhidos a partir da tomada de decisão do cliente, e não da atitude em si de trazer à consciência o significado das imagens oníricas ou a identificação da pulsão do Em Si na psicoterapia. Assim, a tomada de decisão por parte do Eu lógico-histórico do cliente é parte fundamental. "A grande psicoterapia ajuda o indivíduo, mas não the ensina o caminho: o último a decidir é sempre o cliente. Na situação da psicoterapia ele encontra uma escola onde exercitar a própria autenticidade em crescimento contínuo, para construir horizontes sempre novos e mais amplos" (MENEGHETTI, 2010, p. 311).

\section{Metodologia}

Foi conduzida a investigação acerca da tomada de decisão para a autóctise histórica, com o objetivo primário de verificar resultados de tomadas de decisão baseadas no critério onírico, segundo análise ontopsicológica. Como objetivos secundários, buscou-se nessa pesquisa (a) comparar resultados obtidos por sujeitos que decidiram (e agiram de acordo com a diretividade apontada pela análise onírica) com os resultados obtidos pelos que não decidiram, ou seja, não agiram de acordo com a direção dada pela análise do sonho. Tal comparação é feita tendo em vista compreender se há diferenças significativas em relação à manifestação do estado de saúde física, e à manifestação de medo e angústia em decorrência do processo decisório. A investigação também buscou (b) colher, através dos desenhos do teste projetivo (T6D), intenções inconscientes ou conscientes a respeito da personalidade dos participantes e da disponibilidade para o crescimento. Esses dados são, posteriormente, relacionados aos resultados da pesquisa coletados nos demais objetivos. $\mathrm{Na}$ análise comparativa dos resultados dessa investigação, apenas os dados estatisticamente significativos são expostos e problematizados.

A pesquisa teve como participantes indivíduos adultos, jovens de 18 a 42 anos, brasileiros, que concordaram e assinaram o Termo de Consentimento Livre Esclarecido. São trinta participantes, que estão em processo de psicoterapia ou consultoria ontopsicológica.

Como critério de inclusão, está a exigência de que os participantes aceitassem e quisessem participar da pesquisa. Os critérios de exclusão constituíram-se na ausência de resposta de alguma parte da pesquisa e a não aceitação, por parte dos sujeitos, de participar dela. 
Para verificar resultados de tomadas de decisão baseadas no critério onírico, segundo análise ontopsicológica, na entrevista, cada sujeito: (1) responde ao Questionário 1, que verifica condições de saúde e posicionamento em relação à própria existência atualmente; (2) responde ao questionário 2 , auxiliando na investigação de diversos aspectos que caracterizam a anamnese linguística e biografia histórica, a fisionômica e cinésica, a diagnose fideística, referências e valores do sujeito; (3) situa verbalmente e detalha o atual problema ou a situação que enfrenta; (4) conta um ou mais sonhos recentes; (5) desenha de acordo com as diretivas do T6D (técnica projetiva não estruturada, que propõe o desenho de seis ideias universais).

Depois de tais investigações, a pesquisadora expõe ao cliente o direcionamento dado pelo sonho e pelas imagens apresentadas no T6D, junto aos outros cinco critérios diagnósticos propostos pela ciência ontopsicológica. Com base no direcionamento apontado pelo que foi colhido da intencionalidade do Em Si, cada sujeito tomou sua decisão.

Essas cinco etapas constituem o tempo 1 de pesquisa. Duas ou três semanas depois, no Tempo 2 da pesquisa, cada um dos participantes responde novamente ao questionário 1, responde perguntas a respeito da decisão tomada, da percepção de resultado obtido após a decisão e conta o sonho mais recente.

\section{Resultados: análise e interpretação dos dados}

\subsection{Os sujeitos da pesquisa}

Os participantes dividem-se por 17 homens e 13 mulheres. A maioria deles é constituída por gestores e empresários. Depois, observa-se também um número expressivo de designers, advogados e arquitetos.

Os sujeitos, no momento em que participaram da pesquisa, estavam em processo psicoterapêutico por períodos que variam de 1 a 30 meses. De qualquer forma, cada sujeito vive o processo psicoterapêutico de modo particular também no que se refere ao tempo de tratamento. Nos primeiros três a seis meses, é recomendável que o cliente faça sessões semanais ou quinzenais. Porém, depois, ele deve buscar o psicoterapeuta e marcar as próprias sessões apenas quando demanda, e deseja abertura à revisão crítica e à possibilidade de crescimento que cada encontro psicoterapêutico pode proporcionar. Em média, os participantes iniciaram o processo psicoterapêutico há onze meses. 


\subsection{Análise do processo de tomada de decisão na psicoterapia}

Das 30 pessoas participantes, 24 (equivalente a 80\%) decidiram agir de acordo com a diretividade apontada pela leitura do sonho e do T6D, e 6 (20\%) não o fizeram. A decisão, entretanto, não foi medida pelo discurso consciente apresentado pelo sujeito no segundo tempo da pesquisa, mas pelo conjunto de informações colhidas nessa etapa final, que foi constituída por: resposta ao Questionário 1, preenchido novamente, com o intuito de verificar as condições de saúde e posicionamento do sujeito em relação à própria existência na situação atual em comparação com as respostas feitas pela mesma pessoa no tempo 1; resposta à parte final do Questionário 2, em que o participante informa se decidiu ou não seguir as diretivas apontadas pela leitura das imagens oníricas, e se os resultados dessa decisão foram úteis e funcionais, qualitativa e quantitativamente; e o relato de um sonho, feito nos dias recentes, pelo menos duas semanas após o tempo 1 da pesquisa.

Lembrança e esquecimento do sonho: Em psicoterapia, alguns clientes lembram e outros não lembram dos próprios sonhos. Uma vez que já se tenha iniciado o processo de psicoterapia, o ato de não recordar os sonhos, segundo Meneghetti (2012b, p. 38), pode acontecer por duas situações. A primeira refere-se a uma condição, do sujeito, de doença e/o de estar em resistência, isto é, o seu Eu lógico é tão rígido que não deixa filtrar informações; A segunda trata-se de que o sujeito está numa situação de autóctise, por isso a ausência de sonhos estruturais significa que não existem problemas a sinalizar. "De qualquer modo, em linhas gerais, o fato de não recordar dos sonhos é devido à primeira situação, ou seja, à resistência” (MENEGHETTI, 2012b, p. 38). Resistência, como afirma o autor, é um modo de adaptação ao complexo, que de per si não é uma realidade patológica, mas "uma realidade psíquica que se formou em compromisso entre as exigências sociais e as exigências biológicas do indivíduo (MENEGHETTI, 2012a, p. 52). Em outras palavras, a resistência se dá por uma parte do sujeito que não quer conhecer uma outra parte de si. Assim, pode-se compreender a falta de consciência da atividade onírica como um fenômeno que denuncia um tipo de desinteresse pela própria vida; uma barreira que o sujeito impõe à própria mudança.

Nesse estudo, foi constatado que as pessoas que conseguiram aplicar e implementar as mudanças apontadas para a construção da própria autóctise histórica costumam lembrar dos sonhos. Quando foram aplicados os testes do Tempo 1 da pesquisa, três dos 30 participantes que compõem o Grupo Experimental não lembravam de nenhum sonho recente. Nos testes aplicados no Tempo 2, verificou-se que um deles conseguiu implementar as mudanças necessárias, que haviam sido colhidas na diretividade dada pelas constatações que os demais 
critérios diagnósticos permitiram na entrevista do Tempo 1. Os outros dois participantes que não se recordavam das imagens oníricas no Tempo 1 não conseguiram implementar qualquer mudança e continuaram não lembrando do próprio sonho no Tempo 2 desse estudo.

Já no Tempo 2 da pesquisa, pode-se perceber ainda um aumento da resistência por parte daqueles que não implementaram as mudanças necessárias para resolver a situação que enfrentam no momento. A escassez de consciência da atividade onírica afirma a falta de responsabilização pela própria existência.

Tomada de decisão e as alterações na imagem onírica: A cada momento, o fato onírico assinala as predominâncias das vetorialidades no interior do sujeito. O sonho usa uma hierarquia de importância do realismo, colocando em primeiro lugar aquilo que é mais real e urgente (MENEGHETTI, 2010, p. 298). Se a pessoa se responsabiliza e decide agir dirigida à solução do problema, de modo a extingui-lo, o sonho começa a apontar para outros aspectos da existência daquele sujeito, com base na hierarquia de importância daquele momento.

A gráfica onírica "assinala o erro ou o êxito segundo uma hierarquia que parte do indivíduo, prossegue pela esfera da família e dos colaboradores e, no final trata das relações externas" (MENEGHETTI, 2012b, p. 216). A esfera individual compreende o sentido físico de existência. A segunda esfera, afetiva, trata do ambiente de referência afetiva, familiar, emotiva, sexual. A esfera dos colaboradores compreende as pessoas físicas por meio das quais o líder opera e a esfera social constitui o âmbito da atividade concreta, o mundo dos negócios e da atividade econômica.

Nos resultados obtidos, confirma-se a maior incidência de mudança de dinâmica na comparação entre a esfera de necessidades exposta no primeiro sonho contado (no Tempo 1 da pesquisa) e no sonho relatado no Tempo 2. Assim, constata-se que o sonho não obrigatoriamente muda em sua esfera de prioridades quando o sujeito se decide por agir de acordo com a direção apontada pela imagem onírica conscientizada anteriormente. Pode ocorrer, então, que o sujeito decida mudar e comece a agir em direção ao que apontou a imagem onírica exposta no Tempo 1, mas a esfera do sonho não mude em razão de ainda existirem outras problemáticas da mesma esfera a serem resolvidas.

Analisando os participantes que não decidiram, constata-se, que os sonhos seguintes se apresentam na mesma esfera de prioridade do antecedente ou na esfera inferior. Ou seja, enquanto a pessoa não se responsabiliza e dirige sua ação para resolver o problema, a necessidade de solução daquela mesma esfera continua sendo apontada pelo sonho. 
Para detalhar melhor esse aspecto da mudança de esfera do sonho, os resultados demonstram que $54 \%$ das pessoas decidiram e obtiveram mudança na esfera do sonho, $46 \%$ dos participantes decidiram de acordo com a direção dada pela análise do sonho mas não se observou mudança na esfera do sonho, e nenhuma das pessoas que não decidiu apresentou mudança na esfera de necessidades do sonho, entre o período entre o Tempo 1 e o Tempo 2 da pesquisa. É importante ressaltar que a mudança foi medida considerando uma evolução: se o sonho relatado no Tempo 1 apresentava uma problemática da segunda dimensão, ou seja, da esfera familiar e afetiva, considera-se uma mudança de esfera quando no sonho relatado no Tempo 2 da pesquisa é exposta uma situação da esfera 3 (dos colaboradores) ou da esfera 4 (setor social).

Mudança na direção do sonho: Analisando os dados, constata-se que aqueles sujeitos que, por explicitar indícios e resultados, confirmam a decisão de resolver o problema atual com base nas diretivas da imagem onírica apresentam mudanças na direção dada pelo sonho no Tempo 2 da pesquisa. Ou seja, depois de terem começado a agir para resolver a situação, costumam relatar novos sonhos que apontam para uma nova problemática e, portanto, outra direção. Constata-se que $91 \%$ das pessoas que decidiram tiveram mudança na direção apontada pelos sonhos nas semanas seguintes.

A direção dada pela imagem onírica "identifica o quântico de investimento do sonhador na situação dramatizada pelo sonho" (MENEGHETTI, 2011, p. 177). Se compararmos a direção de dois sonhos de um mesmo indivíduo em tempos diferentes, é possível que, se a direção for a mesma, ele não tenha agido de forma a modificar sua situação. "A lógica do sonho é sempre a de intervir para remediar o erro do Eu lógico consciente. No sonho, o inconsciente total indica ao Eu se ele está errando ou não" (p. 200).

Tomada de decisão e elementos do T6D: A técnica projetiva dos seis desenhos permite conhecer as dinâmicas que movem o sujeito, o modo como ele se coloca diante da própria existência e, como o sonho, expõe a problemática que vive atualmente, bem como suas causas e a solução. Algumas categorias foram escolhidas para essa a análise comparativa. Foram constatados dados estatisticamente significativos em relação à dinâmica apresentada nos desenhos da situação atual em comparação à dinâmica presentada nos desenhos da situação futura.

Meneghetti (2012b), ensina que a exposição da mesma dinâmica no desenho da situação atual e no da situação futura significa a ausência de intenção do sujeito de se empenhar para crescer naquele momento. Portanto, os dados sobre esse aspecto do T6D têm 
importância na medida em que revelam a abertura ou a indisposição que traz o sujeito de mudar seu posicionamento diante das condições atuais de existência.

Nos resultados, constatou-se que apenas 3 , das 24 pessoas que decidiram seguir a diretividade onírica, apresentaram a mesma dinâmica nos desenhos da situação atual e futura do T6D. Considerando que, na entrevista, cada sujeito foi informado de que esse aspecto se fazia presente e foi explicado o seu significado, pode-se supor que essas três pessoas abriramse para revisar as próprias escolhas e decidir pelo crescimento depois da intervenção feita no Tempo 1. Compreende-se nessa suposição que cada cliente, quando responsabilizado, pode decidir-se por resolver sua problemática e crescer, a partir do momento em que se abre para revisar-se, sem salvo-condutos.

Implementação da solução indicada: Das pessoas que decidiram e agiram de acordo com a direção apontada na análise das imagens oníricas, 100\% afirmou ter tentado implementar a mudança. Ao dar uma nota de zero a 10 para responder o quanto já conseguiu implementar a solução indicada, as notas variaram de 3 a 8 , sendo que a maioria das pessoas deu nota de 7 a 9 . As notas mais baixas foram frequentes nos casos em que o sujeito relata sentir que, embora já tenha decidido e começado a agir, precisa de mais tempo para sentir os resultados da sua mudança. O intervalo entre Tempo 1 e Tempo 2 é relativamente curto, pois o objetivo do presente estudo foi verificar os resultados mais imediatos depois da tomada de decisão, mesmo que o processo de implementar a solução indicada pelo sonho exigisse mais tempo.

Tomada de decisão concreta e anunciada: Ao responder a pergunta "Você considera ter decidido implementar a solução indicada pela análise do sonho?” o sujeito exprime sua própria percepção sobre a atitude que tomou. Porém, para compreender quem decidiu e quem não o fez, considerou-se aqui a análise do sonho nos tempos 1 e 2, a análise dos desenhos, os resultados (obtidos no percurso histórico existencial e medidos no Tempo 2), e também as respostas dadas do questionário 2. Assim, constatou-se que algumas pessoas $(10 \%$ da amostra total) que pensavam ter decidido não decidiram. Em vez disso, uma das pessoas que demonstra (pelos dados de pesquisa) ter decidido relata sua interpretação de que não decidira (por não ter tido tempo hábil para implementar toda a solução indicada entre os tempos 1 e 2). Muitos dos que realmente decidiram, consideraram ter decidido.

Trata-se de uma confusão relacionada ao modo como o sujeito reflete e interpreta a própria realidade e os fatos que ocorrem ao seu redor. Se a consciência não é exata, o sonho 
pode dar, momento a momento, uma possibilidade de leitura da situação atual com exatidão, independentemente da interpretação fantasiosa (consciente) dos fatos.

Resultados da implementação da solução indicada pelo sonho: Cada sujeito, ao responder sobre os resultados da implementação da diretividade que indicara o sonho, exprime sua percepção, atribuindo uma nota, de 1 a 10, para a utilidade e a funcionalidade do resultado obtido, além de indicar o quanto o foi satisfatório qualitativamente. Considerando-se a resposta dos que seguiram a diretividade apontada pelo sonho, todos os itens questionados são estatisticamente significativos ( $p$-value menor que 0,05$)$. A grande maioria das pessoas atribuiu notas acima de 7 para os resultados obtidos, sendo que $41,6 \%$ atribui nota 10 à funcionalidade e ao quão satisfatório foi o resultado obtido, e $30 \%$ dos participantes atribuem a nota 9 ao resultado obtido. Esse dado demonstra que, ao aplicar a solução indicada pelo sonho, a pessoa tem a evidência, através dos resultados, de que o critério a partir do qual tomou a decisão é válido para si.

\section{Comparação entre as pessoas que decidiram e não decidiram nos tempos 1 e 2:}

Para medir os resultados obtidos pelos sujeitos da pesquisa após implementarem a solução para a qual as imagens oníricas apontaram, foi aplicado um questionário (Questionário 1) nos Tempos 1 e 2 . Assim, foi possível medir e comparar, nesses dois momentos, como o sujeito avalia as próprias condições de saúde, vitalidade e bem-estar corporal, o nível de importância que atribui ao trabalho e ao cuidado de si, o próprio posicionamento em relação aos processos de tomada de decisão e aos fatos que ocorrem na própria vida e a sua relação com os próprios sonhos

No cruzamento desse mesmo questionário nos dois diferentes momentos, e separando as respostas daqueles que decidiram implantar a solução indicada pelo sonho e os que não decidiram, obteve-se muitos resultados estatisticamente significativos. Os sujeitos que não decidiram, e portanto não implantaram a solução indicada pelo sonho, avaliaram o nível de bem-estar no próprio corpo de forma igual ou apresentaram uma significativa diminuição de bem-estar do Tempo 1 para o Tempo 2. Já os que fizeram a decisão e agiram de acordo com as orientações apresentadas na análise do sonho (100\% deles) obtiveram aumento de bemestar no próprio corpo.

Esse dado vai ao encontro do que já aponta a teoria, quando afirma que o Em Si configura-se também biologicamente (Em Si organísmico), sendo critério de sanidade e dando-lhe experiência psicoemotiva. Aqueles participantes que não aplicaram na realidade histórico-existencial as mudanças ou os direcionamentos apontados pela análise das imagens 
oníricas, tendem a permanecer do mesmo modo ou obter resultados sempre inferiores ao esperado e disfuncionais à própria saúde. "Qualquer imagem pode ser uma mediação do sacro de forma vencedora e, em tal caso, deve ser vivida. Essa se distingue pelos resultados: o sujeito sente-se melhor e mais operativo" (MENEGHETTI, 2012b, p. 94).

Da mesma forma, os dados mostram que um maior número de pessoas do grupo das que não decidiram apresentam vitalidade mais baixa no Tempo 2 em comparação ao relato que fazem no Tempo 1, enquanto as que decidiram e aplicaram a solução direcionada pela imagem onírica analisada no Tempo 1, obtiveram no Tempo 2 uma percepção de maior vitalidade. Em relação ao posicionamento dos sujeitos frente aos desafios do cotidiano, outros dados significativos estatisticamente foram encontrados. O relato da presença da sensação de medo se dá apenas naqueles que não se colocaram em abertura para a decisão de implementar a solução apontada pelo sonho. Por outro lado, os participantes que decidiram e agiram de acordo com a direção analisada no sonho, relatam nas respostas o aumento de coragem frente aos novos desafios. É principalmente no Tempo 2 da pesquisa que o grupo dos que não decidiram apresenta maior índice de medo e angústia e o grupo dos que decidiram relata experienciar a alegria.

O processo decisório que tem base na direção dada pelo sonho permite compreender que

\begin{abstract}
no momento em que interajo com um real, o impacto dá o definitivo da forma, a qual faz categoria de realidade. Existem variações que provocam dor e variações que provocam alegria. [...] O homem pode escolher viver com dor ou com alegria. Se quer viver com alegria, deve uniformizar-se à linguagem-base, não é possível do outro modo. Nessa matemática, o homem existe feliz ou não existe) (MENEGHETTI, 2012b, p. 121).
\end{abstract}

Tabela 1 - Síntese dos resultados da pesquisa comparativa entre participantes que decidiram por seguir a diretividade apontada pela análise onírica e os que não decidiram por colocar em prática a solução apontada pelo sonho analisado:

\begin{tabular}{|l|l|l|}
\hline DECISÃO & \multicolumn{1}{|c|}{ SIM (24 PARTICIPANTES) } & \multicolumn{1}{c|}{ NÃO (6 PARTICIPANTES) } \\
\hline \multirow{5}{*}{ SONHO } & $\begin{array}{l}\text { No tempo 1, 95,83\% lembra do } \\
\text { sonho. }\end{array}$ & No tempo 1, 50\% lembra do sonho. \\
\cline { 2 - 3 } & $\begin{array}{l}\text { No tempo 2, 100\% lembra do } \\
\text { sonho. }\end{array}$ & No tempo 2, 50\% lembra do sonho. \\
\cline { 2 - 3 } & $\begin{array}{l}\text { 54\% apresenta mudança na esfera } \\
\text { de prioridade do sonho (do T1 para } \\
\text { o T2). }\end{array}$ & $\begin{array}{l}\text { Não apresenta mudança na esfera } \\
\text { de prioridade do sonho (do T1 para } \\
\text { o T2). }\end{array}$ \\
\cline { 2 - 3 } & $\begin{array}{l}\text { 91\% apresenta mudança de direção } \\
\text { 9\% apresenta mudança de direção }\end{array}$ \\
\hline
\end{tabular}




\begin{tabular}{|c|c|c|}
\hline & do sonho. & do sonho. \\
\hline T6D & $\begin{array}{l}85 \% \text { não apresenta a mesma } \\
\text { dinâmica na situação atual e futura. }\end{array}$ & $\begin{array}{l}50 \% \text { não apresenta a mesma } \\
\text { dinâmica na situação atual e futura. }\end{array}$ \\
\hline $\begin{array}{c}\text { RESULTADO DA } \\
\text { IMPLEMENTAÇÃO }\end{array}$ & $95,8 \%$ entende que decidiu. & $\begin{array}{l}50 \% \text { declara a interpretação de que } \\
\text { decidiu. }\end{array}$ \\
\hline \multirow{5}{*}{$\begin{array}{c}\text { TEMPO } 1 \\
\mathrm{X} \\
\text { TEMPO } 2\end{array}$} & Aumento de bem-estar (100\%). & $\begin{array}{l}\text { Mesmo nível de bem-estar ou } \\
\text { menor }(100 \%) \text {. }\end{array}$ \\
\hline & Aumento de vitalidade (100\%). & $\begin{array}{l}\text { Mesmo nível de vitalidade ou } \\
\text { menor }(100 \%) \text {. }\end{array}$ \\
\hline & $\begin{array}{l}\text { Aumento de coragem frente aos } \\
\text { desafios }(100 \%) \text {. }\end{array}$ & $\begin{array}{l}\text { Aumento dos índices de medo } \\
\text { frente aos desafios }(100 \%) \text {. }\end{array}$ \\
\hline & $\begin{array}{l}\text { Aumento da alegria nos processos } \\
\text { decisórios }(100 \%) \text {. }\end{array}$ & $\begin{array}{l}\text { Presença de medo e angústia nos } \\
\text { processos decisórios }(100 \%) \text {. }\end{array}$ \\
\hline & $\begin{array}{l}\text { Relatam recordar mais dos sonhos } \\
(100 \%) \text {. }\end{array}$ & $\begin{array}{l}\text { Relatam recordar menos dos sonhos } \\
(50 \%) \text {. }\end{array}$ \\
\hline
\end{tabular}

\section{Considerações Finais}

Os resultados da pesquisa confirmam as constatações apresentadas pela ciência ontopsicológica sobre o devir humano e os efeitos da decisão em congruência com a diretividade ôntica que a imagem onírica aponta. Demonstrou-se, nessa investigação, que a natureza humana produz efeitos de acordo com o posicionamento existencial que cada sujeito assume para si, diante das condições histórias que se apresentam e se constroem, momento a momento.

As fenomenologias que, segundo a literatura, são previstas no ser humano que está em constante autóctise histórica de evolução fazem-se presentes nas respostas dos participantes que decidiram e atuaram na prática existencial conforme a direção apontada pelo sonho analisado no Tempo 1 de pesquisa. De fato, foi possível comprovar, com os dados aqui obtidos, que a perda de contato com os sinais que, momento a momento, o próprio critério de natureza aponta tem relação com o aumento dos sintomas de medo e angústia e com a diminuição dos níveis de vitalidade e disposição.

No segundo objetivo secundário, poucas relações calculadas estatisticamente foram significativas. Porém, confirmou-se que já no Tempo 1 de pesquisa, quando os participantes faziam o T6D, a decisão por não mudar a própria situação atual estava feita e aparecia na comparação entre situação atual e situação futura (do T6D). Sem mudanças na forma de colocar-se diante das situações cotidianas, não se dá autóctise histórica. Para esses participantes, a pesquisa indica que a resistência já estava colocada antes da intervenção. Esse dado reforça a importância da continuidade de encontros, característica da proposta de 
psicoterapia, para que o cliente tenha o tempo necessário de compreensão de si e elaboração dos processos de conscientização, a partir dos quais depois pode decidir conforme lhe parecer conveniente. O caráter de intervenção do instrumento psicoterápico depende metodologicamente de um número de encontros, e os resultados da pesquisa demonstram que a decisão por fazer o melhor para si mesmo pode, por vezes, exigir um trabalho contínuo. De qualquer forma, o sujeito pode seguir escolhendo de acordo $\mathrm{cm}$ o critério que lhe parecer mais conveniente, cabendo ao terapeuta auxilia-lo a compreender os resultados obtidos perante a funcionalidade no próprio existir.

A pesquisa demonstrou que o contato com os sinais dados através do sonho exige uma decisão anterior àquela que deve ser tomada na situação que se apresenta para ser resolvida. Essa primeira decisão se refere ao cuidado diário de ir à escola de si mesmo: observar os próprios sintomas, os próprios sonhos e revisar-se levando em consideração que cada ser humano se realiza através de percursos diferentes, uma vez que, já por natureza, é fundado por um princípio que formaliza segundo aquela medida singular.

Os resultados dessa investigação podem ser amplamente explorados para a condução de exercícios em nível didático e exemplificação da aplicabilidade prática do uso do sonho como ferramenta de diagnose e intervenção nos processos de psicoterapia e consultoria. Confirma-se que a análise onírica possibilita resultados assertivos e promotores de saúde. Essa prática é possível mediante o conhecimento do método ontopsicológico por parte do profissional e a atitude do cliente em decidir seguir a direção apontada pela própria imagem onírica, analisada em diálogo psicoterapêutico.

\section{Referências}

GUTHEIL E. A. The handbook of dream analysis. New York, Washington Square Press, 1951.

HAGOPIAN, L. P., FISHER W. W., THOMPSON, R. H., OWEN-DESCHRYVER, J. O., IWATA, B. A., \& WACKER, D. P. Toward the development of structured criteria for interpretation of functional analysis data. Journal of Applied Behavior Analysis, 30 (2), 1997, pp. 313-326.

MACHADO, L. F. S. e ALVES, M. C. L. O uso do sonho em psicoterapia: uma pesquisa com psicólogos da cidade de Franca. IV Congresso de Iniciação Científica, Uni-FACEF, pp. 402-418. Franca-SP, 2009. Disponível em <http://legacy.unifacef.com.br/novo/iv_congresso_de_iniciacao_cientifica/Trabalhos/Inicia\% C3\%A7\%C3\%A3o/Laura\%20Machado.pdf> Acesso em 31 de janeiro de 2014. 
MENEGHETTI, A. Os jovens e a ética ôntica. 3. ed. Recanto Maestro: Ontopsicológica, 2013.

MENEGHETTI, A. Dicionário de Ontopsicologia. 2. ed. Recanto Maestro: Ontopsicológica, 2012a.

MENEGHETTI, A. A imagem e o inconsciente. 4. ed. Recanto Maestro: Ontopsicológica, $2012 b$.

MENEGHETTI, A. O projeto Homem. Recanto Maestro: Ontopsicológica, 2011.

MENEGHETTI, A. Manual de Ontopsicologia. 4. ed. Recanto Maestro: Ontopsicológica, 2010.

MENEGHETTI, A. Imagem alfabeto da energia. 4. ed. Recanto Maestro: Ontopsicológica, 2006.

MENEGHETTI, A. Pedagogia Ontopsicológica, Ontopsicologica Editrice, 2005

MENEGHETTI, A. O Em Si do Homem. Ontopsicologica Editrice, 2004.

MENEGHETTI, A. Filosofia Ontopsicológica. 5 ed. Florianópolis: Ontopsicologica Editrice, 2003.

MENEGHETTI, A. O critério ético do humano. Ontopsicologica Editrice, 2002.

MOURA, Cynthia Borges de; GROSSI, Renata and HIRATA, Patrícia. Análise funcional como estratégia para a tomada de decisão em psicoterapia infantil. Estud. psicol. (Campinas)[online]. 2009, vol.26, n.2, pp. 173-183. ISSN 0103-

166X. <http://dx.doi.org/10.1590/S0103-166X2009000200005> Acesso em 2 de fevereiro de 2014.

VIDOR, Alécio. A epistemologia interdisciplinar: o Homem e seu conhecimento. Santa Maria: UFSM-CE, 1997.

VIDOR, Alécio. A gênese da alienação psicológica e a Ontopsicologia, Ed. UFSM, 1996. 